\title{
Testes de Identificação de Funções Orgânicas: Uma Abordagem Experimental para o Ensino de Química
}

Aline dos Santos Silva* (Graduanda em Licenciatura em Química na Universidade Federal de Campina Grande - UFCG);

Marciano Henrique de Lucena Neto (Professor da UABQ/CES na Universidade Federal de Campina Grande - UFCG);

J osé Carlos Oliveira Santos (Professor da UABQ/CES na Universidade Federal de Campina Grande UFCG)

*E-mail: alinne_2012@live.com

Resumo: Na busca por métodos empenhados na promoção de uma aprendizagem diferenciada, envolvente e preocupada com o real significado que o conhecimento dos conceitos da química têm para os alunos, a experimentação encontra destaque na maioria dos trabalhos científicos direcionados ao ensino de Química. Desta forma, este trabalho foi desenvolvido por bolsistas do PIBID - Subprojeto de Química da UFCG, de modo a despertar o interesse dos alunos no processo de ensino e aprendizagem, envolvendo-os numa proposta diferenciada e significativa, empenhado em utilizar os aspectos cotidianos por meio do tema Química dos Cosméticos e na abordagem da experimentação como ferramenta facilitadora no ensino de funções orgânicas. Os testes de identificação de funções orgânicas oxigenadas foram realizados em alguns cosméticos comumente utilizados no nosso dia-adia e consistiram de experimentos simples de serem realizados pelos alunos, mas que promoveram momentos de discussão sobre o tema e sobre os conceitos necessários ao aprendizado dos alunos.

Palavras-chave: Cosméticos; ensino de química; funções orgânicas; experimentação; contextualização. 


\section{I ntrodução}

Em meio aos mais diversos problemas pelos quais passa a educação brasileira na atualidade, muito tem se questionado quanto aos caminhos que possam nos levar a ter um sistema de ensino de qualidade, apoiado nas reais necessidades de nossos alunos, na busca pelo sucesso escolar e na formação de cidadãos capazes de se posicionar e agir diante da realidade que estão inseridos. De todo modo, há a preocupação e inquietação por parte dos profissionais da educação no sentido de reverter e dar significação à aprendizagem. Isto passa necessariamente pelo processo de reformulação curricular, onde são discutidas duas principais reflexões: o que ensinar e por que ensinar química aos educandos do Ensino Médio.

Segundo Rosa (2012), essa necessidade se justifica no fato de que a química trará para esses educandos um universo riquíssimo em potencialidades desde o aspecto profissional até a sua conscientização como sujeito e cidadão. Ou seja, o currículo direcionado aos alunos, na perspectiva do ensino de Química, deve contemplar a possibilidade de fazer com que os conhecimentos de elementos químicos e reações químicas, por exemplo, possam ser úteis tanto em aspectos cotidianos, como também nas atividades profissionais.

Na busca por uma aprendizagem significativa, definida por Ausubel como um processo pelo qual uma nova informação se relaciona com um aspecto relevante da estrutura de conhecimento do indivíduo (MOREIRA, 2001), a utilização da experimentação no ensino de química está inserida com o objetivo de tornar mais clara e coesa para os alunos os conceitos químicos ministrados em sala de aula, de modo que esta metodologia possa oportunizar a ligação daquilo que os alunos já sabem, com base nas suas observações do cotidiano, com o que estão aprendendo em sala de aula.

De acordo com Guimarães (2009), a experimentação no ensino de ciências pode ser uma estratégia eficiente para a criação de problemas reais que permitam a contextualização e o estímulo de questionamentos de investigação. Esse aspecto inquisitivo característico desta metodologia, talvez seja o ponto chave que o diferencia das práticas educativas que priorizam a transmissão-recepção de conteúdos tão comumente encontrada nas escolas. Logo, podemos dizer que, como ingrediente de ensino, deve-se considerá-la indissociável, sendo ferramenta para o ensino e aprendizagem de química.

Além disso, seja a experimentação com manipulação do material pelo aluno ou demonstrativa, não deve estar associada apenas a um aparato experimental sofisticado, mas sim à sua organização, discussão e análise, o que possibilita a interpretação dos fenômenos químicos e a troca de informações entre o grupo que está realizando o experimento (SCHWAHN e OAIGEN, 2009).

Com base na perspectiva da experimentação como ferramenta facilitadora para o ensino de química, este trabalho empenhou-se na utilização de experimentos denominados testes de identificação de funções orgânicas com o intuito de promover um processo de aprendizagem diferenciada e investigativa, tornando o aluno agente ativo na construção do próprio conhecimento. Esta proposta de ensino foi realizada na Escola Estadual de Ensino Médio e Inovador Orlando Venâncio dos Santos, situada na cidade de Cuité-PB, com uma turma de trinta alunos do $3^{\circ}$ ano do Ensino Médio e teve como objetivo trabalhar de modo contextualizado, junto aos alunos, as funções orgânicas oxigenadas. Para isto, foi inserida a abordagem do tema Química dos Cosméticos com intuito de promover uma problematização inicial abrangendo a contextualização e interdisciplinaridade que o tema oferece. Logo, os testes foram realizados em diferentes cosméticos de modo a analisar qualitativamente a presença de funções orgânicas e compreender sua finalidade em cada produto.

A escolha do tema cosméticos na abordagem dos processos experimentais deveu-se ao fato de que estes produtos estão continuamente presentes no nosso cotidiano e tal aspecto representa a oportunidade de abordar os conceitos químicos de modo contextualizado, uma vez que, desta forma, os alunos poderiam perceber que a química pode ser explicada através de fatos cotidianos com produtos que eles próprios utilizam diariamente, ao invés de métodos para decorar fórmulas e regras, tornando, portanto, o processo de ensino e aprendizagem mais significativo e despertando maior interesse entre os alunos. 


\section{Material e Métodos}

O presente trabalho foi desenvolvido na Escola Estadual Orlando Venâncio dos Santos, localizada na zona urbana do município de Cuité no estado da Paraíba, tendo um período de execução ocorrido entre maio e junho do corrente ano. O público alvo da pesquisa foram trinta alunos de uma turma do terceiro ano do Ensino Médio regular. É importante ressaltar que a referida escola adota o Programa de Ensino Médio Inovador, o qual possui os chamados macrocampos na proposta do Projeto de Redesenho Curricular. Logo, as aulas foram ministradas pelos bolsistas do PIBID/QUíMICA/UFCG/CES em um dos macrocampos obrigatórios do programa: a Iniciação Científica e Pesquisa.

A abordagem realizada no decorrer deste trabalho empenhou-se na possibilidade de promover entre os alunos a construção de conhecimentos por meio dos aspectos interdisciplinares e contextualizados promovendo, assim, a aprendizagem dos conceitos inerentes da química orgânica buscando uma melhor compreensão das funções orgânicas oxigenadas comumente utilizadas na fabricação de cosméticos comercializados no nosso cotidiano. Deste modo, o trabalho pode ser organizado em quatro momentos: apresentação do tema, estudo das funções orgânicas oxigenadas, aulas experimentais e avaliação das atividades (SILVA et al., 2014).

A etapa inicial de apresentação do tema consistiu em inserir os alunos na importância de se estudar os cosméticos na busca pelos conhecimentos químicos, bem como das outras áreas do saber e dos aspectos cotidianos oportunizados pelo estudo do tema. Logo, foi apresentada aos alunos uma problematização do tema de forma contextualizada e interdisciplinar, no qual foram apresentados aspectos como: definição e classificação dos cosméticos, riscos, aspectos históricos, químicos e biológicos, etc. com o intuito de que os alunos se posicionassem de forma crítica frente ao modo como a temática cosméticos é veiculada na sociedade. As aulas que compunham esta etapa foram realizadas com a utilização de slides, vídeos e leituras de textos sobre os conhecimentos que envolvem o tema.

A etapa seguinte foi direcionada ao estudo das funções orgânicas oxigenadas. Para isto, foram realizadas aulas teóricas com a utilização de quadro, pincel, slides, textos e vídeos nas quais foram apresentadas aos alunos as funções orgânicas oxigenadas, seus grupos funcionais, nomenclaturas, sempre relacionando à exemplos do cotidiano mais precisamente na ocorrência em cosméticos.

Após o estudo das funções orgânicas oxigenadas em sala de aula, foram realizados experimentos no laboratório de ciências da escola (Figura 1).

Figura 1 - Realização dos experimentos com a turma

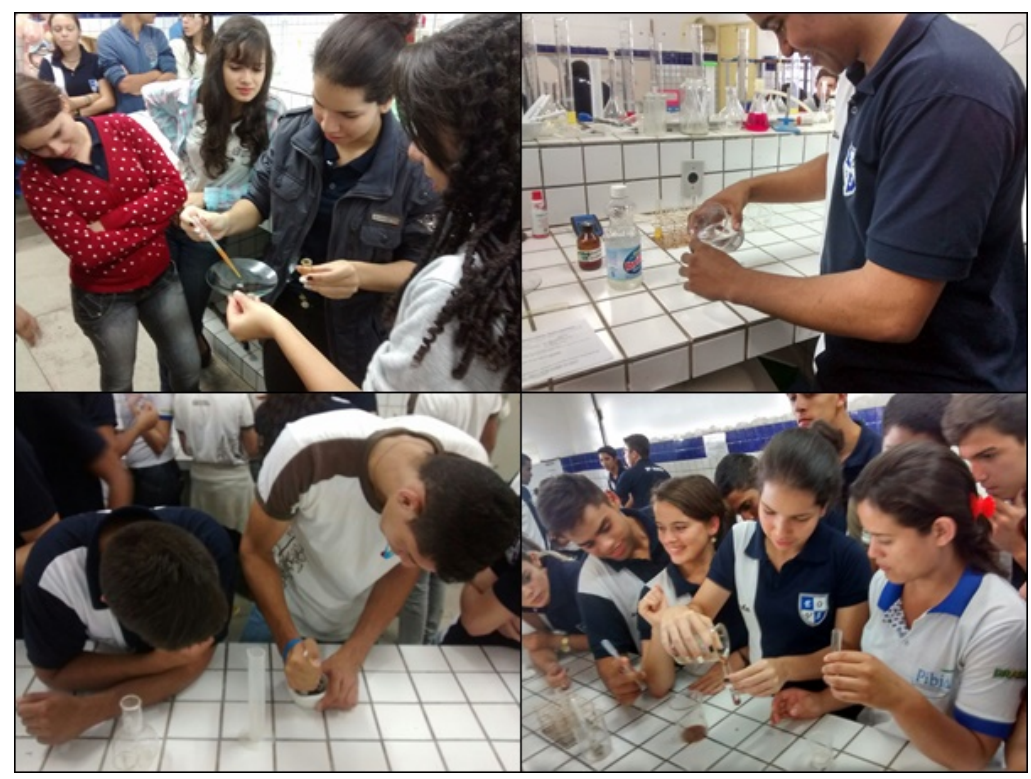

Fonte: Autoria própria 
Os experimentos consistiam de testes de identificação de funções orgânicas em cosméticos comumente utilizados no nosso cotidiano. O Quadro 1 a seguir resume os reagentes necessários na identificação das respectivas funções orgânicas, bem como os resultados esperados para as reações de acordo com pesquisas na literatura.

Quadro 1 - Testes de identificação de funções orgânicas

\begin{tabular}{|c|c|c|c|}
\hline $\begin{array}{l}\text { Função orgânica } \\
\text { oxigenada }\end{array}$ & Amostra(s) & Solução & Resultado esperado \\
\hline Álcool & $\begin{array}{c}\text { Álcool etílico } \\
\text { Leite de colônia } \\
\text { Perfumes } \\
\text { Anti-transpirante }\end{array}$ & Ácido crômico & Precipitado verde \\
\hline Cetonas & $\begin{array}{c}\text { Água } \\
\text { Removedor de esmaltes } \\
\text { Álcool }\end{array}$ & $\begin{array}{l}\text { 2,4-dinitrofenil- } \\
\text { hidrazina }\end{array}$ & $\begin{array}{l}\text { Precipitado amarelo } \\
\text { avermelhado }\end{array}$ \\
\hline Aldeídos & $\begin{array}{c}\text { Água } \\
\text { Esmalte incolor }\end{array}$ & $\begin{array}{l}\text { 2,4-dinitrofenil- } \\
\text { hidrazina }\end{array}$ & $\begin{array}{l}\text { Precipitado amarelo } \\
\text { avermelhado }\end{array}$ \\
\hline $\begin{array}{l}\text { Ácidos } \\
\text { carboxílicos }\end{array}$ & Creme para espinhas & $\begin{array}{l}\text { Bicarbonato de } \\
\text { sódio }\end{array}$ & $\begin{array}{l}\text { Desprendimento de } \\
\text { gás carbônico }\end{array}$ \\
\hline Fenóis & $\begin{array}{l}\text { Cravo da índia em álcool } \\
\text { Canela em álcool }\end{array}$ & Hidróxido de sódio & Coloração marrom \\
\hline
\end{tabular}

Os materiais utilizados nos experimentos eram simples, o que facilitou sua reprodução pelos alunos. De modo geral, foram necessários béqueres, conta-gotas, vidros de relógios, tubos de ensaio e bastões de vidros. Para a realização dos experimentos, os alunos receberam roteiros experimentais, os quais orientavam em termos de proporções no preparo das soluções e nas misturas a serem realizadas. Ao fim de cada experimento, os alunos se reuniam para responder questões pós-laboratório presentes nos roteiros, destinados a promover uma discussão dos resultados obtidos nos procedimentos experimentais. Em seguida, as perguntas do pós-laboratório eram respondidas em conjunto com os pibidianos, esclarecendo-se dúvidas e explicando detalhadamente os experimentos.

Ao fim das atividades, realizamos sua última etapa por meio da aplicação de questionário destinado a obter um parecer da metodologia utilizada de acordo com a avaliação dos próprios alunos. O questionário continha quatro questões e seus resultados estão explanados no tópico seguinte deste trabalho.

\section{Resultados e Discussão}

Podemos iniciar a apresentação dos resultados obtidos nesta proposta metodológica a partir do questionário final aplicado aos alunos. Com base nestes resultados, nos será possibilitado abrangermos nossas discussões por meio das observações realizadas no decorrer das atividades priorizando a participação, envolvimento e desenvolvimento dos alunos.

O questionário aplicado ao final das atividades foi direcionado aos trinta alunos da turma em pesquisa e continha quatro questões, as quais encontram-se explanadas no Quadro 2 abaixo. 
Quadro 2 - Questões do questionário final aplicado aos alunos

1- A etapa de apresentação do tema cumpriu, na sua opinião, com o objetivo de promover uma aprendizagem de forma mais dinâmica e motivadora?

2- Com a utilização dos experimentos realizados, como você classifica sua aprendizagem dos conceitos ministrados nesta etapa?

3- O projeto, de modo geral, apresentou algum diferencial, na sua opinião, quando comparado às outras metodologias as quais você está habituado?

4- Ao longo do projeto, você adquiriu conhecimentos que serão importantes e aplicados no dia-a-dia?

Fonte: Autoria própria

As repostas obtidas pelos alunos apresentaram-se muito positivas às atividades realizadas e categorizamos as mesmas de modo a facilitar nossa interpretação dos resultados obtidos. Na questão inicial, a maioria dos alunos respondeu que a etapa inicial cumpriu com o objetivo de promover uma aprendizagem mais dinâmica e motivadora como podemos visualizar no Gráfico 1 a seguir.

Gráfico 1 - Resultado da questão 1

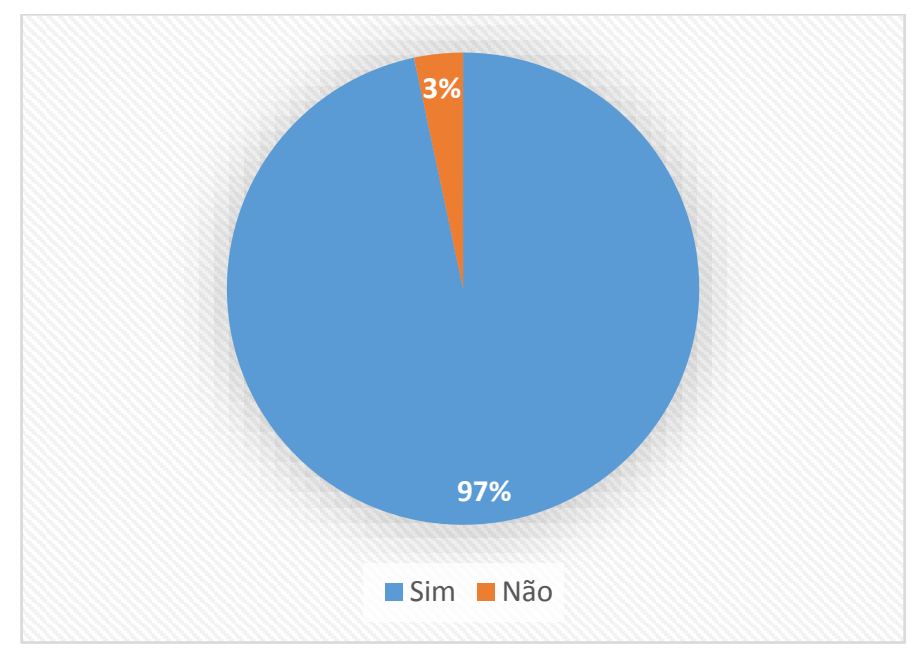

Fonte: Dados da pesquisa

Dentre as justificativas dadas pelos alunos nesta questão, encontramos:

$\checkmark$ Sim, porque não houve pressão, fizemos por livre e espontânea vontade e isso traz maior conhecimento;

$\checkmark$ Sim, principalmente nas discussões onde toda a turma interagiu e, de forma dinâmica, aprendeu;

$\checkmark$ Não, não me senti motivado.

Na segunda questão, notamos que a maioria dos alunos demonstraram ter gostado da etapa experimental classificando, assim, como "ótima" a sua aprendizagem dos conceitos ministrados nesta etapa. O Gráfico 2 abaixo apresenta este resultado. 
Gráfico 2 - Resultado da questão 2

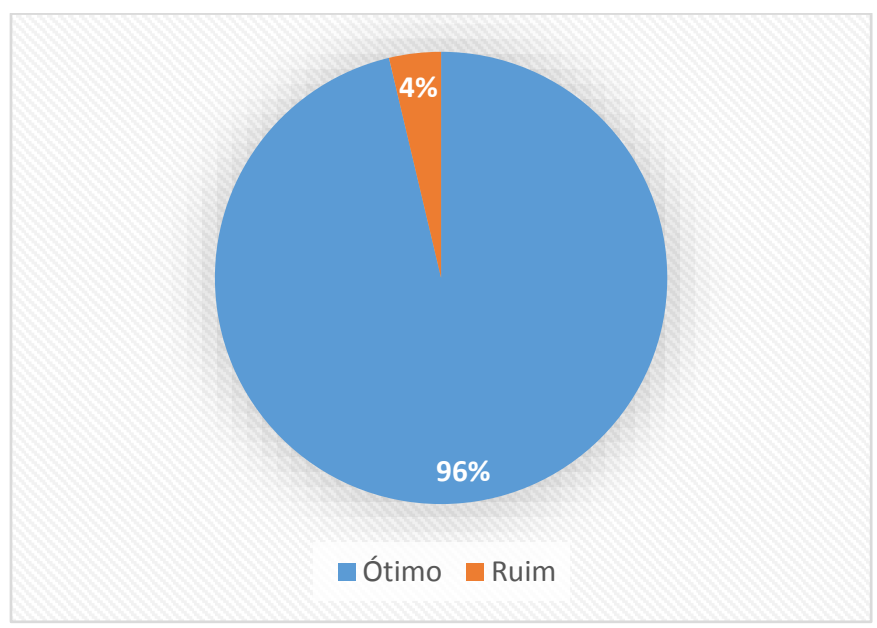

Fonte: Dados da pesquisa

Os alunos também apresentaram suas justificativas às respostas dadas e, dentre elas, selecionamos as seguintes:

$\checkmark$ Ótimo, já que foram usados produtos do nosso dia-a-dia o que faz nós termos um maior entendimento do assunto de química na prática;

$\checkmark$ Ótimo, porque saiu das teorias e não ficou aquela coisa muito cansativa, ficando mais fácil de compreender o assunto;

$\checkmark$ Ruim, pela quantidade de alunos e pouco material.

A terceira questão representou uma surpresa muito boa para nós, pois os alunos foram unânimes quanto ao fato de as atividades apresentarem um diferencial quando comparadas às metodologias a que estão habituados. Vejamos no Gráfico 3 abaixo.

Gráfico 3 - Resultado da questão 3

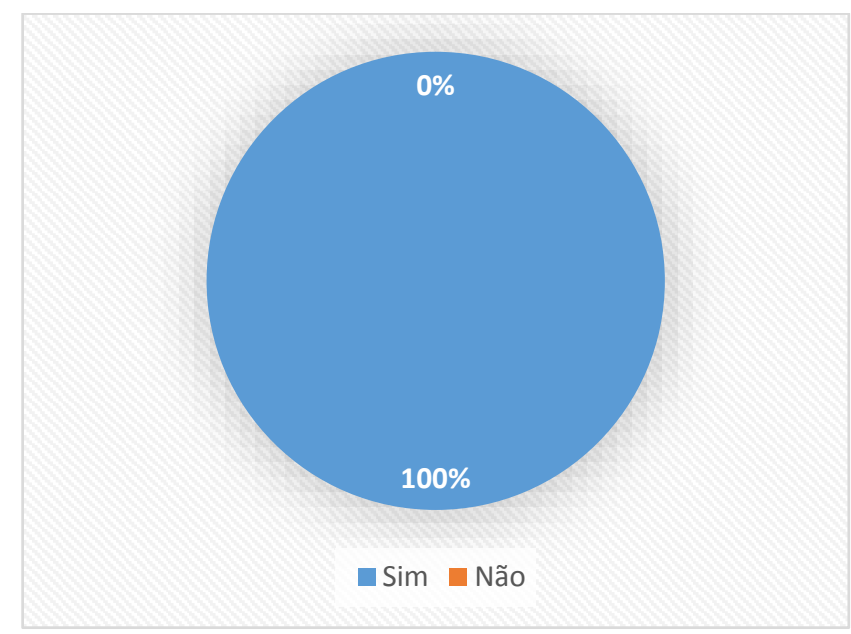

Fonte: Dados da pesquisa 
As justificativas dadas pelos alunos foram muito favoráveis à nossa abordagem, de modo que selecionamos as seguintes:

$\checkmark$ Sim, pois geralmente as aulas são muito monótonas e chatas sem nenhum tipo de atividade que prendam a atenção dos alunos;

$\checkmark$ Sim, porque quebrou a rotina da forma como foi visto o assunto;

$\checkmark$ Sim, porque normalmente não temos esse tipo de aula com experimentos, etc.

Na questão final do questionário, os alunos também foram unânimes quanto aos conhecimentos adquiridos no decorrer das atividades e sua aplicação no seu cotidiano. O Gráfico 4 abaixo mostra que cem por cento dos alunos relatam que irão aplicar seus conhecimentos a partir do que foi visto nas atividades realizadas.

Gráfico 4 - Resultado da questão 4

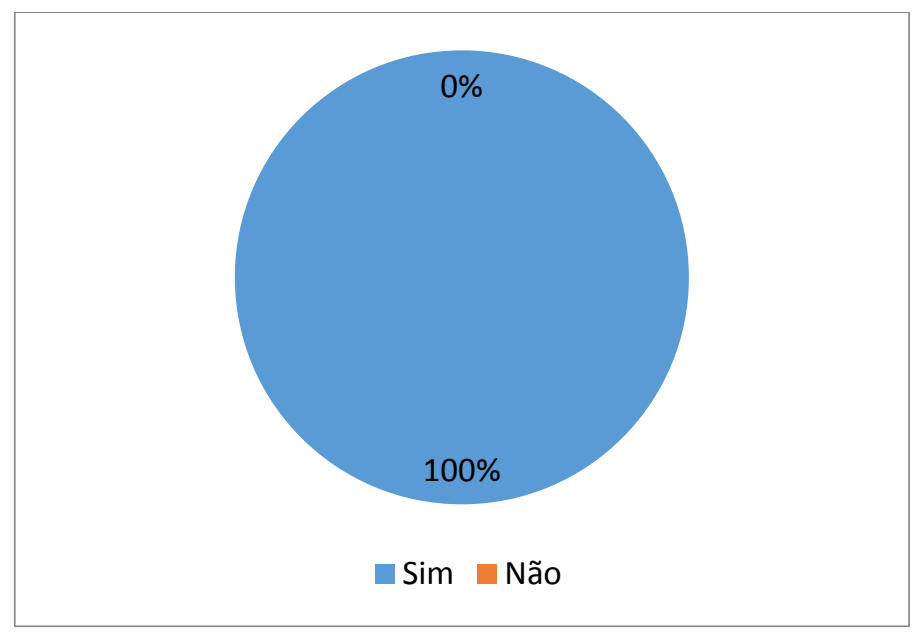

Fonte: Dados da pesquisa

Algumas justificativas citadas foram:

$\checkmark$ Sim, por exemplo nos riscos que os cosméticos nos trazem o que muitas vezes não sabemos;

$\checkmark$ Sim, para o ENEM, na compra de cosméticos, identificar suas composições e utilização dos mesmos;

$\checkmark$ Sim, pois se trata de algo que utilizamos diariamente e é essencial.

Percebe-se claramente que, de acordo com os resultados acima mencionados, as atividades realizadas mostraram aspectos muito positivos quanto ao envolvimento e a aprendizagem dos alunos. Todas as etapas que abrangeram uma participação direta dos alunos, promovendo sua participação e oportunizando a troca de experiências, contribuíram para um melhor processo de ensino e aprendizagem, uma vez que foi notável a necessidade dos alunos de estarem inseridos em todo o processo, ao invés de simplesmente ficarem observando o professor falar enquanto eles "absorvem" as informações.

Com relação aos resultados obtidos nos experimentos realizados todos apresentaram-se de acordo com o esperado na literatura. A utilização dos roteiros experimentais no decorrer dos procedimentos facilitou a execução dos experimentos e permitiu uma melhor autonomia dos alunos, apesar da nossa orientação. Isso, de acordo com nossas observações, fez com que os alunos se sentissem agentes ativos da própria aprendizagem, despertando maior interesse na execução e na observação dos resultados. Este fato contribuiu, também, para que os alunos se motivassem a responder as questões pós-laboratório, de modo que seu empenho em compreender os motivos que ocasionaram tais transformações foi favorecido, uma vez que estes pesquisaram, tiravam dúvidas e buscavam esclarecimento dos fenômenos por eles observados. 


\section{Conclusões}

De acordo com as observações realizadas no decorrer das atividades propostas e com base nos resultados obtidos por meio do questionário final aplicado aos alunos, esta pesquisa nos levou a concluir a importância de se utilizar a experimentação no processo de ensino e aprendizagem no ensino de química, reforçando o que dizem os muitos trabalhos publicados na literatura em se tratando desta metodologia. Vimos, no entanto, que é necessário realizarmos um planejamento das atividades, pesquisa e um processo de inserção dos alunos nas práticas de modo que estes possam vivenciar a aprendizagem que, por sua vez, deve ocorrer de modo significativo aos alunos. Para isto, o tema cosméticos foi inserido contemplando as reais necessidades que os conceitos ministrados representam na realidade cotidiana dos alunos, trabalhando deste modo os aspectos contextualizadores e interdisciplinares. Sendo assim, podemos concluir que as etapas propostas em seu desenvolvimento, apresentaram resultados positivos à aprendizagem dos alunos e à aplicação destes conhecimentos em seu cotidiano, mostrando que a química pode, e deve, ser vista como uma ciência capaz de esclarecer as nossas vivências cotidianas, devido sua abrangente presença em nosso dia-a-dia.

Identification tests of Organic Functions: an experimental approach to chemistry teaching

Albstract: In the search for methods engaged in promoting a differentiated learning, engaging and concerned about the real meaning that knowledge of chemistry concepts have for students, experimentation is featured in most scientific papers directed to the teaching of chemistry. Thus, in order to arouse the interest of students in the teaching and learning by involving them in a differentiated and meaningful proposal, committed to using everyday aspects through cosmetics Chemical theme and experimentation approach as an enabling tool for teaching of bodily functions, this work was developed by fellows PIBID - Activity Chemistry UFCG. The oxygenated organic functions identification tests were carried out in some cosmetics commonly used in our daily life and consist of simple experiments to be performed by the students, but that promote moments of discussion on the issue and on the very fruitful concepts to student learning.

Keywords: cosmetics; chemistry education; organic functions; experimentation; contextualization

\section{Referências bibliográficas}

GUIMARÃES, C. C. Experimentação no ensino de química: Caminhos e descaminhos rumo à aprendizagem significativa, Química Nova Na Escola, v. 31, № 3, 2009.

MOREIRA, M. A.; MASINI, E. F. S. Aprendizagem significativa: a teoria de David Ausubel. Centauro: São Paulo, 2001.

ROSA, D. L. Aplicação de metodologias alternativas para uma aprendizagem significativa no ensino de química. Monografia (Especialização em Ensino na Educação Básica) - Departamento de Educação e Ciências Humanas do Centro Universitário Norte do Espírito Santo da Universidade Federal do Espírito Santo. 97 p. 2012.

SCHWAHN, M. C. A.; OAIGEN, E. R. Objetivos Para o Uso da Experimentação no Ensino de Química: A Visão de Um Grupo de Licenciandos, in: Anais doVI I ENPEC. UFSC. Florianópolis: 2009. 
SILVA, A. S.; SOUSA, A. S.; ARAÚJO, D. S.; COSTA, E. O.; LIMA, J. A. C.; ARAÚJO, M. L. M.; LIMA, R. C. S.; SANTOS, J. C. O.; PORTO, T. N. V. À Procura da Vitamina C: Uma Proposta Pedagógica Desenvolvida pelo PIBID-Química como Forma de Abordar a Interdisciplinaridade no Ensino de Química. In: Anais do 540 CBQ. ABQ. Natal: 2014. 